\section{An extended apparatus for measuring aggression in humans*}

\author{
RUSSELL G. GEEN and DAVID STONNER \\ University of Missouri, Columbia, Missouri 65201
}

An extension of Buss's device for measuring human aggression is described. and the status of aggressive response latency as an indicator of aggressive motivation is discussed. An experiment is described in which measures of latency correlated negatively with those of shock intensity, and both discriminated between Ss who were motivated to aggress and those who were not.

Much of the work on aggression in humans has utilized an apparatus, first designed by Buss (1961), by means of which one person is led to believe that he is giving electrical shocks of varying intensity and duration to another person. Variations on the basic instrument have been used by several investigators (e.g., Geen \& Berkowitz, 1967; Walters \& Thomas, 1963), but basically the apparatus consists of 10 switches, purportedly governing 10 increasing intensities of shock, but actually terminating in a readout upon which the number of the button being pressed is observed. In the most common experiment, the $S$ is instructed to give shocks as punishment for errors made by an experimental confederate. The instrument has been quite popular because it yields objective and easily measured indices of aggression. In experiments where $S s$ have been instigated to aggress, measures of shock intensity have successfully discriminated between these and noninstigated control Ss (e.g., Geen \& Berkowitz, 1967; Geen \& O'Neal, 1969); the measure has also been found to correlate positively with subjectively reported feelings of anger (Geen, Rakosky, \& O'Neal, 1968).

Recently, in our laboratory, we have developed an extension of Buss's apparatus which yields both the more conventional measures of shock intensity and duration and a measure of the amount of time that elapses from the onset of the signal telling $S$ to give the shock to the actual shock response. Conversion of existing instruments to permit this measurement is quite simple, involving only the addition of two relay circuits, as outlined in the diagram in Fig. 1. The SPST switches labeled A-E are customary and are used for conveying information from the confederate (C) to $S$ on the lamp in series with them. $C$ then makes prearranged errors in forming concepts on the basis of this information. The SPDT switches

*This study was supported by Grant GS-2748 from the National Science Foundation to the senior author.
$(1-10)$ are the 10 shock buttons which terminate in a one-plane readout (Industrial Electronics Engineers, Van Nuys, California, Model 10-0011-1909-L). All switches make momentary contact. Relay $R_{2}$ is $N C$ but is opened by depression of any shock switch, activating a clock $\left(\mathrm{M}_{2}\right)$, which is a standard laboratory timer with the switch externalized (Lab-Chron Model 402; Lab-Line Instruments, Melrose Park, Illinois). When C presses the SPST switch labeled "Wrong," a lamp is lit on S's panel, signifying that $\mathrm{S}$ is to shock $\mathrm{C}$. Simultaneously, Relay $R_{1}$ is closed, activating Clock $\mathrm{M}_{1}$ and closing the circuit between the second set of contacts on both $R_{1}$ and $R_{2}$. When $R_{2}$ opens, therefore, as $\mathrm{S}$ presses a shock button, the circuit through the primary of $R_{1}$ is broken, opening that relay and stopping $M_{1} . M_{1}$ thus measures time elapsed between onset of the "Wrong" lamp and S's delivery of shock to $\mathrm{C}$, while $\mathrm{M}_{2}$ measures the length of time $\mathrm{S}$ holds down the shock switch.

We expected that the amount of time between the signal to shock and the shock itself would be less for Ss who had been instigated to aggress against $C$ than for those who had not been so instigated. This could be due to two processes. Ss who have been previously attacked by $\mathrm{C}$ will be motivated to counterattack. In this case, the attack upon $S$ can be thought of as a drive stimulus which elicits responses of retaliation, one feature of which should be a relatively short latency. On the other hand, Ss who have not previously been attacked may manifest . conflict between the tendencies to shock and to refrain from shocking a person against whom they have not been motivated to aggress. This conflict would be expected to produce a period of indecision and relatively long time lapses between signal and response.

An experiment was carried out to test our expectation. In the study, Ss in one condition were first attacked by $\mathrm{C}$, then allowed to attack in return, while Ss in a second group were not attacked by $\mathrm{C}$ but were allowed to attack him. A third condition was added to control for possible effects of increased generalized drive in the attacked Ss, which could conceivably

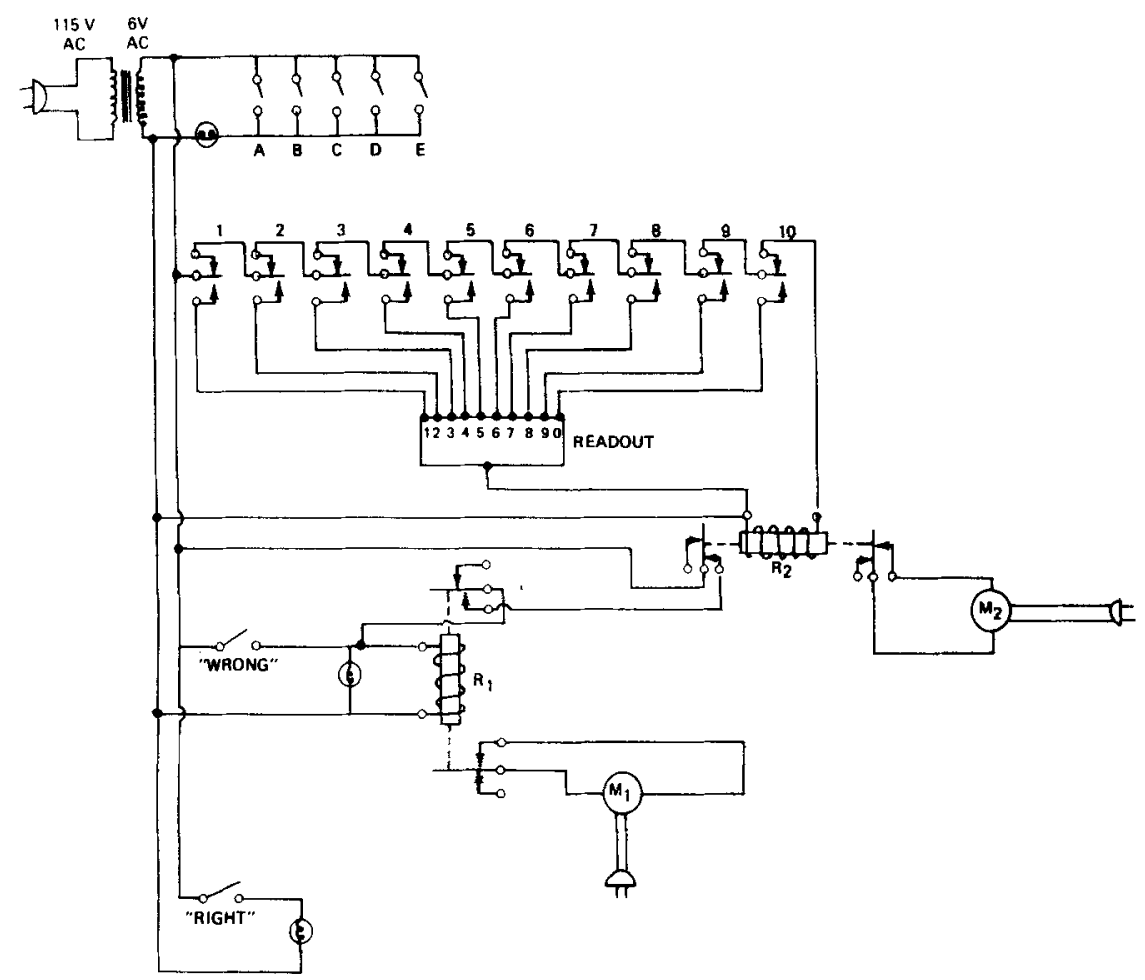

Fig. 1. Diagram of apparatus. 
activate a buttonpressing response independently of any motive to aggress. Ss in this group were attacked by $\mathrm{C}$, but used the shock buttons on the apparatus for what was described as merely the control of a light on C's panel.

\section{Subjects}

\section{METHOD}

Ss were 30 males who participated in order to receive points toward their grades in general psychology.

\section{Procedure}

$\mathrm{S}$ and $\mathrm{C}$, who posed as a $\mathrm{S}$, were informed that the experiment was designed to measure effects on learning of both punishment and the degree of similarity between the punishing agent and the learner. The two were seated in separate booths. $S$ was then given a list of 12 controversial statements and instructed to express his opinion on each. He was further told that $\mathrm{C}$ would give him either a strong or weak shock, at his own discretion, each time he did not agree with $S$ (presumably to motivate $S$ to express himself carefully). ${ }^{1}$ To Ss in Groups 1 and 3 , $\mathrm{C}$ gave two mild shocks $(0.15 \mathrm{~mA})$ and six fairly strong ones $(0.5 \mathrm{~mA})$ by means of a Harvard induction stimulator. To Ss in Group 2, $\mathrm{C}$ gave only two mild shocks. Following this, $\mathrm{E}$ allowed $\mathbf{S}$ and $\mathbf{C}$ to draw lots to decide who would be the teacher and who the learner in the learning situation. The draw was rigged so that $S$ was designated teacher. He was then instructed to present programmed stimuli to $\mathrm{C}$ by means of one set of buttons on the apparatus, to await C's response, and to press one of 10 buttons each time $\mathrm{C}$ made an error. Ss in Conditions 1 and 2 were told that the buttons represented 10 increasing intensities of electric shock which $\mathrm{C}$ would receive; Ss in Condition 3 were told that any one of the buttons activated an error light on C's panel and thus any one could be pressed. In the session which followed, $C$ made 30 errors on 40 trials according to a prearranged schedule.

\section{RESULTS}

One-way analyses of variance for all three dependent measures revealed significant between-treatments effects for both shock intensity $(F=10.62$, $\mathrm{df}=2,27, \mathrm{p}<.005$ ) and shock latency $(\mathrm{F}=9.65, \quad \mathrm{df}=2,27, \quad \mathrm{p}<.005)$. A Duncan multiple-range test comparing all means for latency showed that Ss in Condition 1 manifested significantly shorter latencies than Ss in the other two conditions, who did not differ from each other. The analysis of shock durations showed no effects for treatments. Pearson product-moment correlation coefficients among the three measures were calculated from the data for Ss in Conditions 1 and 2. The only significant correlation was between shock intensity and latency $(\mathrm{r}=-.62, \mathrm{df}=19, \mathrm{p}<.005)$.

\section{DISCUSSION}

The results of this study indicate that a measure of shock response latency successfully discriminates between Ss who have been instigated to aggress and those who have not. The measure also correlated significantly with shock intensity, which has previously been shown to be a meaningful measure of aggression. Whether our measure is indeed one of latency, which suggests some underlying aggressive drive produced by the prior attack, or rather one of inhibition in the nonattacked Ss is not readily apparent from the data. However, the fact that nonattacked Ss showed response times equal to those of Ss who believed that the buttons did not shock $C$ suggests that nonattacked Ss may not have been inhibited so much as they were simply not motivated to aggress. For the time being, in either case, we may conclude that the apparatus used in this study does yield an empirically useful measure of aggression.

\section{REFERENCES}

BUSS, A. The psychology of aggression. New York: Wiley, 1961.

GEEN, R. G. Perceived suffering of the victim as an inhibitor of attack-induced aggression. Journal of Social Psychology. $1970,81,209-215$

GEEN, R. G. \& BERKOWITZ, L Some conditions facilitating the occurrence of aggression after the observation of violence. Journal of Personality, 1967. 35, 666-676.

GEEN, R. G. \& O'NEAL, E. C. Activation of cue-elicited aggression by general arousal. Journal of Personality \& Social Psychology, 1969, 11, 289-292.

GEEN, R. G.. RAKOSKY, J. J., \& O'NEAL, E. C. Methodological study of measurement of aggression. Psychological Reports, 1968, 23, 59-62.

WALTERS, R. H. \& THOMAS, E. L. Enhancement of punitiveness by visual and audiovisual displays. Canadian Journal of Psychology, 1963, 17 244-255.

\section{NOTE}

1. Complete details of the procedure are given by Geen et al (1968). 